\title{
Improving mobility in the Madrid Metropolitan Area
}

\author{
S. Carpintero \& V. Maraña \\ Madrid Polytechnic, Spain
}

\begin{abstract}
This paper examines some of the most outstanding transport infrastructure projects implemented in the Madrid Metropolitan Area during the period 20032007, namely: the multibillion refurbishment of the main urban orbital Madrid Calle 30; the construction of three new tram lines as part of a broader scheme that has entailed a total $58 \mathrm{~km}$ extension of the underground network; the implementation of various intermodal transport interchanges; and, finally, the commissioning of a new railways tunnel connecting the city's two main stations. The paper addresses the key aspects of these projects, such as the technical challenges encountered and their innovative procurement schemes. In most of the cases the projects have been implemented through Public Private Partnerships. Finally, the paper captures some conclusions drawn from these experiences that may be found of interest for other Public Bodies that aim at implementing successfully projects of similar size and complexity. These conclusions include the need of upfront planning, coordination of administrations, strong legal framework and adequate capabilities of stakeholders, including funders, sponsors, contractors and public administrations. Keywords: Madrid, PPP, intermodality, transport interchange, urban tram.
\end{abstract}

\section{Introduction}

A considerable number of major transport infrastructures have been built in the metropolitan area of Madrid during the period 2003-2007 promoted by the various public administrations and entities which hold competencies in different aspects of the transport policy: planning, economics, construction, operation and/or maintenance.

Spain, and in particular Madrid, stands currently at the forefront in the implementation of this type of project, as a result of the steady high levels of 
investment of the last decade that have aimed at boosting economical and social growth in order to reach European standards. The PPP law approved in 2003 (Law 13/2003 of 23rd May) has also contributed to a successful infrastructures policy, as a considerable number of the projects across all sorts of sectors have been (and are being) procured through Public Private Partnerships. This law has recently been integrated in the broader new general law of Public Procurement passed in 2007.

Some of the projects implemented in Madrid during this period stand currently as international flagships due to their technical complexity, innovation, size and/or tight deadlines. The following can be considered as the most outstanding out of all:

- The refurbishment and revamping of the main urban orbital, Madrid Calle 30; with a total capital cost in excess of EUR 3bn the project currently stands as the biggest PPP transaction in continental Europe.

- The construction of three new tram lines, with a total length of $27 \mathrm{~km}$ and EUR 520m of capital cost. These lines are part of a broader scheme for the extension of Madrid underground network, which has entailed the construction of more than $80 \mathrm{~km}$ of new infrastructure.

- The implementation of five new intermodal transport exchanges in the main road accesses to the city. The total capital of the programme was worth more than EUR 400m.

- Finally, the commissioning of a new $8.5 \mathrm{~km}$ long railway tunnel between Madrid two main stations. The tunnel is aimed at resolving the capacity constraints of the old connection, and the total investment accrued EUR $550 \mathrm{~m}$.

\section{Description of the projects}

\subsection{Madrid Calle 30}

\subsubsection{Description of the project}

The 'Madrid Calle 30' project for the upgrade of the city's main orbital (MC-30) was worth more that EUR 3.5 billion of capital value and stands, so far, as the largest PPP initiative in continental Europe. The project has been praised internationally for its innovative procurement and contractual arrangements, as well as for its unprecedented technical achievements.

The MC-30 was designed as an outer ring road for the city of Madrid. The construction of the first sections started in the late sixties, and the orbital was completed in the early nineties. Before the refurbishment the facility was approximately $35 \mathrm{~km}$ long and the number of lanes ranged from six to ten, depending on the section. The asset has been superseded by urban development and additional outer rings completed in the last decades.

The traffic around the whole MC-30 ring has a big impact on the rest of the city and its metropolitan are, and the project was particularly aimed at improving traffic congestion issues experienced within the inner ring. 
The project was conceived as an ambitious intervention for revamping the old facility in order to improve its capacity and functionality. Major interventions included:

- milling and resurfacing of the entire infrastructure;

- refurbishment of the main junctions in order to improve functionality;

- undergrounding northbound and southbound carriageways alongside the river course in the western side; the new tunnels will also allow for additional lanes to improve the capacity;

- construction of a new by-pass to separate orbital movements from radial movements;

- $\quad$ works on the surface such as the redesign and development of green areas, including riverside areas, historical sites and city landmarks; and, finally,

- additional interventions such as the upgrade of the sewage system alongside the river.

The undertaking included the construction of the world's largest urban tunnel to date, with a length of $12 \mathrm{~km}$. The overall length of tunnels - including main carriageways and slip-roads - amounted $42 \mathrm{~km}$. The world's two largest earth pressure balanced (EPB) tunnel-boring machines (TBM), with $15.2 \mathrm{~m}$ of diameter each, were used for this purpose, having delivered impressive performance on site.

The project is also expected to bring important social and environmental benefits, such as:

- the reduction of accident rates;

- the reduction of fuel consumption and carbon emissions; as well as,

- $\quad$ savings in journey times.

\subsubsection{SPV contractual arrangements}

Madrid Calle 30, the Special Purpose Vehicle (SPV) for the project, was set up in 2004 as a Public Company funded entirely by the Madrid City Council. By the end of that year Madrid City Council agreed allowing a private shareholder entering the company and, subsequently, launched a tender process for the selection of a private partner and operation and maintenance service provider.

A consortium led by Spanish contractors ACS and Ferrovial was appointed as preferred bidder. The consortium entered a 35 year concession contract executed in 2005 , in which obligations for the private partner included the provision of $20 \%$ equity of the of the SPV and a subordinated loan facility.

The SPV was also obliged to carry out the initial construction works (which had already commenced), as well as undertaking the operation and maintenance, included major renewals, of the infrastructure during the contract period. The payments to the SPV include a basic fixed payment an additional payment that is subject to performance and availability adjustments.

The construction was developed by means of sixteen construction contracts which started in September 2004: these were entered initially by the City Council which transferred its liability to the SPV. All the works were completed by the last quarter of 2007. During this period the most reputable Spanish 
contractors were involved simultaneously in different locations throughout the facility, making it the busiest construction site in Europe. Additionally, the SPV launched a contract for the design and construction of a new traffic control centre, which currently hosts all traffic management operations of Madrid City Council. All the contractual deadlines were met in spite of the tight construction schedule and deadlines.

The SPV also entered an Operation and Maintenance service Agreement with the service provider EMESA, which is entirely owned by the private partner of the SPV.

So far the project has benefited from the advantages of the PPP contractual model, which include, among others, the following:

- greater capacity of fund raising;

- effective risk transfer;

- introduction of initiative and innovation of the private sector, resulting in a better value for money for the public sector in relation with the services procured.

....However, Eurostat determined that the final contractual arrangement had not resulted in a satisfactory transfer of risks to the private sector. Madrid Calle 30 is since then considered as a Public Company, and its balance sheet consolidates with the rest of Madrid City Council accounting.

\subsection{Madrid underground extension programme 2003-2007}

\subsubsection{The programme}

Under the 'Madrid Underground Extension Programme 2003-2007' the Madrid Regional Government implemented the biggest package of improvements in the underground network ever undertaken in a similar programme. Following similar programmes initiated in 1995 and 2003, this ambitious package entailed:

- the construction of over $80 \mathrm{~km}$ of new lines and 80 new stations, worth EUR 3.3bn of capital cost;

- acquisition of new rolling stoke valued at EUR 694bn; and,

- EUR $344 \mathrm{~m}$ investment in new depots and extension of the existing facilities.

The programme was largely aimed at meeting the increasing transport demand in suburban areas of Madrid, as well as the renovation of existing assets. It was expected that over 700.000 commuters would benefit from the programme. Some municipalities adjacent to Madrid have gained access to the metro network for the first time through the northern and eastern extensions, the so called 'Metronorte' and 'Metroeste'.

\subsubsection{The new tram lines}

One of the flagships of the 2003-2007 programme was the implementation of three new tram lines in different locations within the Madrid metropolitan area, namely:

- Line T1 Pinar de Chamartín - Las Tablas, 5,5km long and anticipated annual demand of 6.3 passengers. 
- Line T2 between Colonia Jardín and Pozuelo, with a total length of $8.7 \mathrm{~km}$ and an anticipated average demand of $9.1 \mathrm{~m}$ passengers per year.

- Line T3 between Colonia Jardín and Boadilla: total extension of $13.5 \mathrm{~km}$ and foreseen average demand of 8.5 passengers per year.

\subsubsection{Benefits of urban trams}

Electrically powered urban Trams have thrived in cities all over the world in the last few years as an alternative to fossil fuelled private and public options. In particular, in Spain, more than fifteen (15) trams have been, or are being, implemented by different local and regional Authorities. Trams are back in the front line of urban 'green' transport policy as a means of improving the mobility in urban and metropolitan environments while addressing simultaneously environmental challenges.

The key benefits of the tram lines against alternative systems are considered to be, among others, the following:

- a more efficient use of energy in comparison with other means of transport, as the trams are powered with electricity generated from renewable sources;

- reduction of carbon emissions;

- energy savings derived from the break system, which generates energy that can be re-conducted to the distribution system and reused to power the trams;

- economic efficiencies in relation with mass transit metro systems where the transport demand is not justified;

- increase of punctuality, as normally the trams are segregated from the space shared by the rest of the surface transport;

- increase of the quality of life and accessibility to all users; and,

- improvement of the urban space, as their implementation is normally undertaken in conjunction with other urban and landscaping interventions.

The Madrid Regional Government has also opted for reviving this system, which had been given up in the last century in favour of bus services, trolleybuses and conventional metro system.

The new tram lines have been procured through PPP schemes which include the construction, operation and maintenance of the infrastructure and rolling stock during a period of 30 years. The capital investment for the three lines was in excess of EUR $750 \mathrm{~m}$.

\subsubsection{The procurement process}

Initially, the Madrid Regional Government arranged the construction of the three lines through the traditional public procurement rout. Works commenced in 2005 upon contractors being appointed by the public entity Mintra. Under this initial arrangement Mintra would eventually have granted the relevant concessions for the operation of the tram lines

Mintra (Madrid Infraestructuras del Transporte) is a public body established in 1999 by the Madrid Regional Government. Its main role is the management 
and implementation of the infrastructure projects within the Madrid region, including, among others, the following:

- budget programming;

- development of feasibility studies, preliminary and final designs;

- land and right of way purchase;

- procurement of construction works;

- supervision of works;

- maintenance of existing infrastructures; and,

- purchase of new rolling stock

However, shortly after, Eurostat determined Mintra was considered as a public company under the European Accountancy System. Hence, in the light of this decision, all its projects would consolidate, for Public Accounting purposes, as part of the Regional Government public debt. The unexpected decision of Eurostat urged the Regional Authorities to modify the initial procurement arrangement, seeking removal of the projects off its balance sheet.

The Regional Government sought minimising eventual delays in the deadlines committed for the commissioning of the new tram lines. A new contractual arrangement was swiftly developed by the Authority, which entailed a new risk transfer profile for the deal and which also took into consideration the existence of the construction contracts already in place. As an eventual early termination of these contracts would have resulted in delays in the whole programme schedule, the Regional Government held negotiations with all the contractors, which accepted in all cases entering a subrogation of the original contracts, whereby the Concessionaire would be replacing Mintra as contractual party.

Under the new contractual arrangement the new tram lines were finally procured through concession schemes granted by Mintra, which include the construction, operation and maintenance of the lines. The scheme also required the provision of new rolling stock. This was supplied by Mintra to the respective concessionaires, which obligations included its purchase and maintenance. Finally, the procurement of a new depot was also included under the concession for the $\mathrm{T} 1$ line.

The total duration of the contract was set forth at 30 years. During this period the concessionaire will receive payments from the grantor based on the actual demand; the payments are also subject to performance adjustments. However, the revenue risk is capped at $+/-30 \%$ of the anticipated demand. The fare per passenger paid by the concession grantor and the cap of the revenue risk were subject to bid by the contenders at the tender stage.

\subsection{Implementation of five new transport interchanges}

\subsubsection{The programme}

During this period the Madrid Regional Government has also procured five new transport interchanges in strategic locations of the city, coinciding with the main road accesses. The programme is worth total EUR $400 \mathrm{~m}$ of capital investment, and includes the following new facilities: 
- Plaza de Castilla new transport interchange, worth EUR 120m and anticipated daily demand of 350k passengers.

- Príncipe Pío new transport interchange, will be used daily by $160 \mathrm{k}$ passengers and its capital cost amounted EUR 50m.

- Plaza Elíptica new transport interchange, with EUR 36m of capital cost and $126 \mathrm{k}$ daily users.

- Plaza de Castilla new transport interchange, worth EUR 102m of capital cost will be used by $60 \mathrm{k}$ passengers a day.

- Extension of Moncloa transport interchange: the project entails EUR $97 \mathrm{~m}$ of investment; the new facilities will be used by $360 \mathrm{k}$ daily passengers.

\subsubsection{The role of transport interchanges}

Transport interchanges aim at easing access to different means of transport and, ultimately, reducing journey times. They result in a better integration of transport modes and hence rendering public transport more attractive and easy to use.

The role played by such facilities in a metropolitan area is crucial, as a big proportion of the journeys generated cover long distances and entail different means of transport and different lines.

Since established in 1985, the Madrid Regional Transport Authority (Consorcio Regional de Transportes de Madrid) has played a significant role in the integration of different means of transport within the Madrid metropolitan area, and the implementation of transport interchanges for interurban buses has been one of its most praised achievements. The Authority holds competencies for transport regulation within the Region of Madrid including, among others, the following roles:

- transport planning;

- transport tariff integration; and

- modal integration.

The current transport demand between Madrid capital city and the metropolitan area is twice as big as the demand encountered by the Transport Authority upon its inception. In 2004 the total annual demand reached 276m; out of these, the interurban buses journeys represented $13.4 \%$, and the $53 \%$ of the journeys originated, or with destination, in the metropolitan area outside Madrid city. During this period the idea of intermodality has been broadly extended among users, transport operators and policy makers.

The first generation of transport interchanges for interurban buses was implemented in Madrid between 1986 and 1993; these incipient facilities were all built in the surface in a similar way than those already existing for urban buses. During the period 1994-1997 a second generation addressed intermodality more effectively by introducing underground levels that allowed the implementation of more platforms while easing the access to the metro network. The most representative example of this period is the Moncloa Interchange built in 1995. Finally, the new interchange of Avenida de América, completed in 2000, included, among other improvements, an express tunnel that allowed direct access for the interurban buses, segregating these from the rest of 
the traffic in surface. The project was the first funded by the private sector and procured through a concession scheme.

The design and procurement of the new interchanges implemented during the period 2003-2007 are largely inspired on the lessons learnt in the Avenida de América experience. The design concepts have been improved by enhancing functionality, passenger flow, information systems, safety and security, and urban integration.

\subsubsection{The procurement scheme}

The latest generation of interchanges have all been procured through concession schemes. The concession entails the construction, maintenance and operation of the bus terminals for a total period of 35 years.

The revenue sources for the concessionaire are:

- $\quad$ transport fares for each long distance coach using the facilities;

- transport fares for each passenger using interurban bus services (with destination or originated in the Madrid metropolitan area);

- car park fares;

- retail units; and,

- other sources of revenue such us publicity, office space lettings or vending machines.

\subsection{Other projects: construction of the new railway tunnel between Atocha and Chamartín}

The most outstanding of the rest of major infrastructure projects undertaken during this period by other public administrations, is the new $8.5 \mathrm{~km}$ railway tunnel between the two main stations of the city: Atocha, in the south, and Chamartín, in the north.

The project has been procured by the Spanish Ministry of Transport and Public Works (Ministerio de Fomento); the total construction costs accrued Eur $550 \mathrm{~m}$ and the construction period was 4 years. The project also entails the construction of two new stations at Nuevos Ministerios and Sol, two of the busiest transport interchanges in the city.

The new connection is aimed at easing the capacity constraints of the old tunnel, commissioned in the 1960s. As a result, railway commuters will benefit from journey savings up to 15 minutes, and southern lines will be extended to Chamartín, avoiding $35 \mathrm{k}$ of daily changes in the overcrowded platforms at Atocha station. Additionally, the two new intermediate stations will improve access to the metro network from the interurban railway lines, known as Cercanías.

The execution of the new tunnel has required very tight coordination between the three public administrations (central, regional and local) as a number of services in the existing networks have been disrupted during the works and due to the necessity of coordinating traffic management measures in the surface.

The new tunnel crosses the urban centre throughout its historical areas of most significance, hence a very tight monitoring of archaeological findings have 
also been required. The numerous findings encountered during the excavation works have resulted in several modifications of the construction programme.

The tunnel was successfully commissioned in 2008 , and only the works in the new Sol station remain currently uncompleted.

\section{Conclusions: reasons for success}

\subsection{Coordination of different public authorities}

The simultaneous implementation of all these infrastructure projects has entailed a close coordination between all the public bodies involved. The coordination has been necessary at all levels and stages of the process:

- During the definition of the strategic and long term regional and metropolitan transport policy, to ensure an integrated transport policy consistent with other regional policies: e.g. environmental, regional and urban planning and/or economic.

- Coordination with transport policies implemented by other public administrations at different levels which hold competencies in this field: i.e. central, regional and local public administrations.

- Coordination of the different public bodies and operators to ensure a comprehensive approach to transport solutions, ensuring that the demand is met through maximum functionality and intermodality of the network, allowing fare integration and, ultimately, providing economic efficiency. This has proved to be a success given the size of the and projects and the number of bodies involved: Mintra, Metro de Madrid, Consorcio Regional de Transportes, Cercanías, etc.

- Finally, coordination has also been crucial during the construction period, for most of the projects have been implemented simultaneously. This has entailed, among others, the planning of disruptions, diversions and/or closures of existing transport services; coordination of site access and construction schedules and issuance of the relevant permitting. Coordination at this level has allowed minimizing disruptions to public transport users and negative impacts on third parties.

\subsection{Existence of a pipeline of mature projects ready for procurement}

In order to ensure a quick and adequate response to the transport needs it has been necessary that the relevant public authorities allocate enough time and resources for the development of strategic and long term transport policies, as well as for the preparation of the projects before these are included as part of a mature pipeline ready for implementation.

In general, the preparation processes should not underestimate the amount of time required to address properly the different aspects of the project, for which it is necessary to develop, among others, preliminary risk analyses, demand forecasts, technical feasibility studies, cost benefit analysis, etc. 


\subsection{Strength and capability of the public sector}

It has been necessary to count on a strong public sector with enough resources and PPP knowledge, capable to lead the preparation and implementation of the projects, as well as their monitoring during the operational phase.

The sophistication of some of the contractual arrangements for the definition of performance standards and remuneration of the concessionaire requires specific procurement and commercial knowledge. This requires normally additional training programmes or outsourcing, to ensure officials can deliver their role during the whole procurement process successfully.

\subsection{Strength and capability of the private sector}

During the last few decades Spain has developed a vast number of infrastructure and building construction programmes resulting in a highly skilled private sector that was ready to undertake the challenges entailed by the different projects described. The existence of such strong and sophisticated private sector has been crucial for the successful implementation of these programmes.

Spanish contractors, sponsors and lenders are, indeed, leading the international league tables of their respective sectors in relation to the provision of transport infrastructure, especially through PPP schemes.

\subsection{Adequate legal framework for the provision of infrastructures and public services through public private partnerships}

Concessions in Spain are regulated through the Law 13/2003 of 23rd May. Since the law was passed in 2003 it has been crucial for the procurement of infrastructure and public services projects by different public administrations at central, regional and local levels. The provisions of this law were recently included in a broader public procurement law passed in 2007. This legal framework has created what has been perceived by all the different stakeholders as a reliable environment. Projects of the size and nature of those described previously could not have been implemented through PPP arrangements had the parties involved perceived any uncertainty in the legal framework and political support. In that sense, the maturity of the legal framework is also deemed crucial for the successful implementation of the projects.

The Spanish law provides a comprehensive framework and sets forth provisions in relation to the key aspects for the successful implementation of PPP ensuring value for money for the public sector and allocating risk in an effective, yet realistic manner.

\subsection{Adequacy of the tender mechanism}

Although the current legal framework for public procurement addresses a number of different tender procedures, Spanish public administrations opt generally for the open competitive process for the awarding of concession contracts. 
This mechanism has proved to be an efficient procedure, simple and quick to apply, and that ensures competitive strain throughout the whole process. It also reduces bidding costs for all the parties.

Other tender procedures broadly used in other countries such as the competitive and the negotiated dialogue have been avoided in favour of the open procedure, aiming at avoiding negative outcomes experienced in other countries due to the lack of administrative and technical capability of the public sector.

The tender process have also been praised for its transparency in the evaluation process, as the evaluation criteria and scoring method are clearly defined at the beginning of the process and is not subject to discretionary decisions of the contracting authority and allows effective comparison across the different proposals.

Finally, the open procedure requires generally less time in comparison to other options. The tender process has a sole stage and is based on very simple and clear rules. In general, the total duration of the process is between five (5) and eight (8) months, out of which three to four are for the preparation of the proposals by the contenders and three to four for the evaluation process.

Full funding commitment by the lenders is not required by the submission of the proposals, and financial close is reached upon awarding of the concession.

\section{References}

[1] Mijangos, J. (2007): "Urban Passenger Transport in Madrid. Advances in Intermodality", Pre-proceeding of the 23rd PIARRC World Congress, World Road Association, Paris.

[2] Monzón, A. et al (2005): "El programa de mejoras de la M-30 en el contexto de una estrategia de movilidad sostenible para Madrid", Revista de Obras Públicas, $n^{\circ} 3.454$.

[3] Observatorio Económico (2007c): "Impacto económico de las infraestructuras viarias en la Ciudad de Madrid", Observatorio Económico, Área de Gobierno de Economía y Empleo, Ayuntamiento de Madrid.

[4] Pardeiro, A.M. y Monzón, A. (2005): "La reconversión de la M-30: de cinturón interurbano a distribuidor urbano", Carreteras: Revista Técnica de la Asociación Española de la Carretera, $n^{\circ} 141$, págs. 70-79.

[5] Vassallo, J. and Perez de Villar, P. (2009): "Social equity and efficiency of the public transport system in Madrid", Revista de Obras Públicas, nº 3.494 